\title{
Clinical Reasoning: Mechanical thrombectomy for acute ischemic stroke in the setting of atrial myxoma
}

Prasanna Tadi, MD, Rafey Feroze, MD, Pranav Reddy, Pemmasani Sravanthi, MD, Nasir Fakhri, MD, Ryan McTaggart, MD, Shadi Yaghi, MD, and Brian Silver, MD

Neurology ${ }^{\circledR}$ 2019;93:e1572-e1576. doi:10.1212/WNL.0000000000008321

\author{
Correspondence \\ Dr. Tadi \\ tadip@upmc.edu
}

\section{Section 1}

A 23-year-old woman with a medical history of migraines and tobacco use was brought to the emergency department with a 2-hour history of acute onset, right-sided hemiplegia and expressive aphasia. The patient had never experienced similar symptoms in the past. Her migraines occurred 3 times weekly, lasted 1-2 days, and were characterized by photophobia along with bilateral headache of a right-sided predominance. She took acetaminophen and ibuprofen for pain relief. Her family history was significant for a sister with glucose-6-phosphate dehydrogenase deficiency.

The patient was afebrile on admission with a blood pressure of $112 / 62 \mathrm{~mm} \mathrm{Hg}$ and regular heart rate of 64 . General physical examination was within normal limits. Upon neurologic examination, she was awake, alert, tracking, able to follow all commands, but displayed expressive aphasia. Cranial nerves testing was significant only for right homonymous hemianopsia and right facial droop consistent with upper motor neuron facial weakness. Motor examination revealed flaccid right-sided hemiplegia. Loss of sensation to light touch was noted on the right. The patient was given an NIH Stroke Scale (NIHSS) score of 19. Identified stroke risk factors included smoking, obesity, and oral contraceptive use.

\section{Questions for consideration:}

1. What is the differential diagnosis for the right-sided hemiplegia and expressive aphasia?

2. Is the patient's presentation explained by her migraine history?

\section{GO TO SECTION 2}




\section{Section 2}

The differential diagnosis for acute onset, right-sided hemiplegia and expressive aphasia includes stroke, seizure, demyelinating disease, metabolic encephalopathy, complicated migraine, or functional neurologic dysfunction (e.g., conversion disorder). The patient's presentation was unlike her usual migraines as she did not complain of bilateral headache/ photophobia and had new right-sided motor weakness. Due to acute onset of symptoms and objective findings on neurologic examination, the most likely diagnosis was thought to be stroke. The clinical syndrome was localized to the contralateral middle cerebral artery (MCA) territory. Her head CT scan was negative for acute blood, but was found to have an ASPECTS score of 7/10 (figure, A) due to hypodense left caudate, lentiform, and insular regions, raising suspicion for an acute left MCA infarct. Given the absence of hemorrhage on head $\mathrm{CT}$ and concern for ischemic stroke, the patient received IV thrombolytic therapy ( $\mathrm{tPA}$ ) which, when given within 4.5 hours of symptom onset, has been shown to improve chances of a good functional outcome by establishing reperfusion. ${ }^{1}$

CT angiography showed occlusion of the left supraclinoid internal carotid artery and left M1 segment with mild collateralization of the left M2 segment (figure, B). Diffusion-weighted
MRI showed extensive restriction in the left MCA territory including the left caudate head and lentiform nucleus corresponding to infarction (figure, C-E). Recent trials (such as Endovascular Treatment for Small Core and Proximal Occlusion Ischemic Stroke [ESCAPE], Extending the Time for Thrombolysis in Emergency Neurological Deficits: IntraArterial [EXTEND IA], and Multicenter Randomized ClinicalTrialof Endovascular Treatment for Acute Ischemic Stroke in the Netherlands [MR CLEAN]) have shown that in the presence of large artery occlusions, mechanical thrombectomy in a select group of patients is associated with improved functional outcomes. ${ }^{1}$ Since the patient described in the present case had a large vessel occlusion and presented within 6 hours from symptom onset, she underwent mechanical thrombectomy for removal of the left M1 occlusion (figure, F and G) with a resultant thrombolysis in cerebral infarction score of 3 . She had an excellent response to thrombectomy, with minimal residual aphasia on examination and an NIHSS of 10 approximately 24 hours following thrombectomy. She was started on daily aspirin and statin therapy.

\section{Question for consideration:}

1. What are the most likely etiologies of acute ischemic stroke (AIS) in a young patient?

Figure Preintervention and postintervention acute ischemic stroke and atrial myxoma imaging

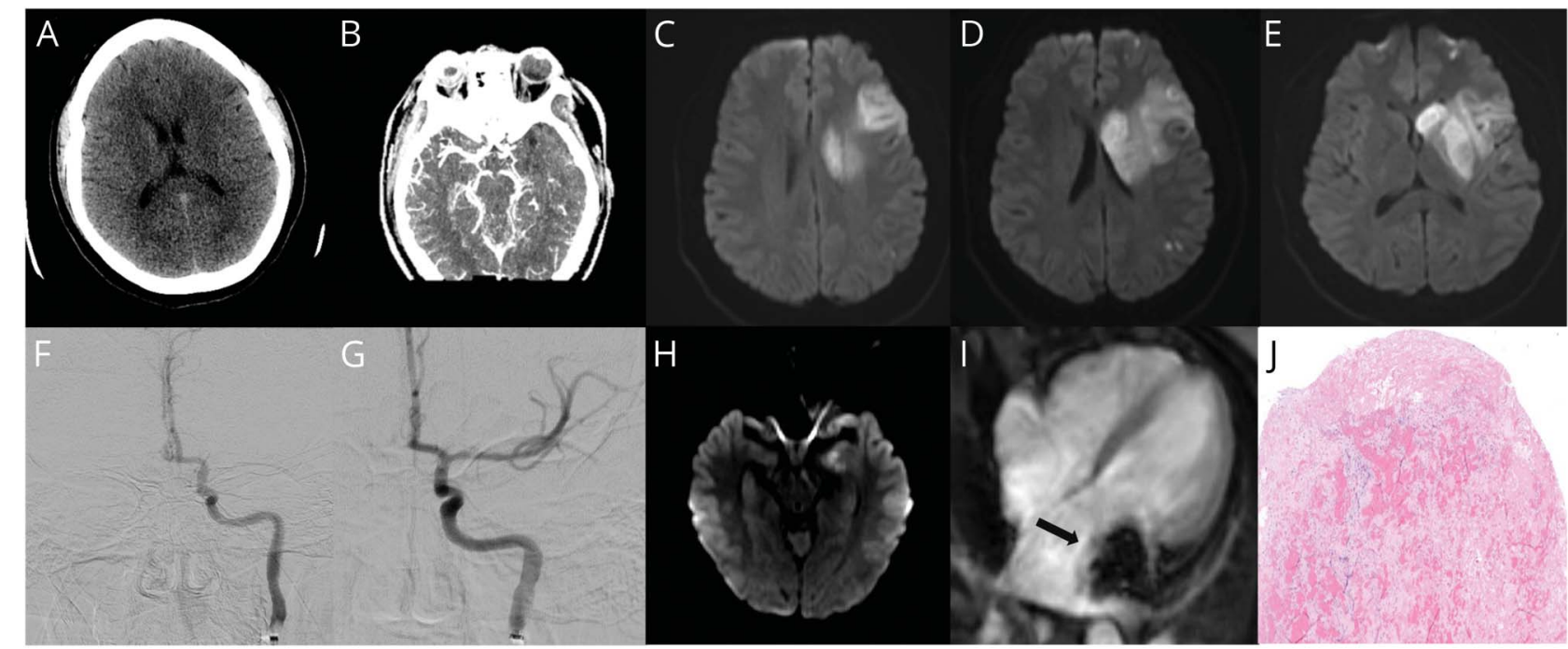

(A) Initial noncontrast head CT. (B) CT angiography shows left middle cerebral artery (MCA) territory large vessel occlusion. (C-E) Prethrombectomy diffusionweighted MRI shows restriction in the left MCA territory. (F) Prethrombectomy angiogram demonstrates impaired filling of the left MCA at its origin. (G) Postthrombectomy imaging shows resolution of flow in the left MCA. (H) Post-thrombectomy MRI on the 7th day of hospitalization shows new diffusion restriction in the left midbrain. (I) Cardiac MRI illustrates atrial myxoma in the left atrium (arrow). ()) Histology of resected myxoma tissue with superficial fibrin thrombi (scale bar and unit unavailable).

GO TO SECTION 3 


\section{Section 3}

Likely stroke mechanisms in young adults include cardioembolism, sickle cell anemia, dissection, moyamoya, vasculitis, drug abuse, hypercoagulable states, and neurogenetic disorders. $^{2}$ As part of the stroke workup in the aforementioned patient, a transthoracic echocardiogram was done, which demonstrated a large $(>5 \mathrm{~cm})$ mass in the left atrium that prolapsed across the mitral valve into the left ventricle during diastole. A follow-up cardiac MRI showed a lobulated amorphous $4.9 \times 2.4 \times 2.5 \mathrm{~cm}$ mobile left atrial mass with attachment to the left atrial wall immediately inferior to the left atrial appendage (figure, I). These radiologic findings raised suspicion for an atrial myxoma, which was thought to have caused an intracranial embolus resulting in the patient's presentation. Further bloodwork revealed a low-density lipoprotein level of 81 and $\mathrm{HbAlC}$ of 5.1. The patient's hypercoagulation workup returned with antithrombin III of 89 , total protein $S$ of 98 , free protein $S$ of 60 , and protein $C$ of 110 , and was negative for both lupus anticoagulant and a prothrombin gene mutation.

\section{Question for consideration:}

1. What is the next step in managing the patient? 


\section{Section 4}

Recent systemic thrombolytic therapy made immediate surgical resection of the atrial myxoma risky due to the likelihood of bleeding complications. However, on the 7th day of hospitalization, the patient developed new-onset diplopia. She underwent a repeat MRI, which demonstrated a new infarct in the left midbrain (figure, $\mathrm{H}$ ). Given this stroke recurrence and with the goal of preventing a third embolic event, the decision was made to proceed with surgery for cardiac tumor resection. Intraoperative findings revealed that the tumor occupied $80 \%$ of the left atrium. The origin of the mass was found to be in between the origins of the left superior and inferior pulmonary veins. Due to its size, it was excised in piecemeal fashion. Grossly, the excised aggregate of friable, semitranslucent, tan-red tissue fragments was $7 \times 6 \times 1 \mathrm{~cm}$. The myxoma consisted of patchy hemorrhage, focal hemosiderin deposition, and superficial fibrin thrombus (figure, J). The patient developed no postsurgical complications and had no recurrent ischemic events. When seen in stroke clinic for 2 months follow-up, she was found to be recovering well, with an NIHSS of 4.

\section{Questions for consideration:}

1. Is there a high likelihood of recurrent strokes in a patient with existing cardiac myxoma?

2. What are some considerations regarding risk management of resection in such patients?

\section{Discussion}

Incidence of AIS in young adults (18-49 years of age) has been increasing over the last decades, with improved survival of patients with predisposing conditions such as congenital heart disease and sickle cell anemia along with a rise in traditional stroke risk factors such as hypertension, hypercholesterolemia, and obesity in younger individuals. Stroke in young patients causes tremendous loss of work-years and incurs long-term health costs. A high index of suspicion for diagnosing stroke is required, as other more common and benign diagnoses like hemiplegic migraine may divert the clinician's approach and cause loss of valuable time. When treated promptly, disability can be mitigated and further investigation for the cause of stroke can be initiated.

Cardioembolism, often due to congenital or acquired heart disease, is the most common cause of stroke in children. ${ }^{3}$ With improved treatments for structural cardiac malformations of infancy, a larger fraction of these patients are now entering young adulthood and have an increased risk of stroke. In developing countries, rheumatic mitral valve disease most frequently predisposes young adults to cardioembolic stroke whereas patent foramen ovale and mitral valve prolapse are more common in the western world. Hemoglobinopathies, most notably sickle cell, are also associated with cerebral thrombosis, with exchange transfusion being the mainstay of treatment and limited evidence regarding the efficacy of tPA in this setting. In addition, migraines, illicit drug use, oral contraceptives, and pregnancy have been identified as independent risk factors for AIS in young adults. ${ }^{4}$

If a common cause of AIS is not apparent, rarer etiologies must be considered. Among these, arterial dissection resulting from cervical trauma or connective tissue disorders (EhlersDanlos, Marfan syndrome, osteogenesis imperfecta) has been found to account for approximately $20 \%$ of ischemic stroke in young adults. ${ }^{4}$ Other rare causes include infectious meningitis, vasculitis (inflammatory arteritis or induced by infectious hepatitis/HIV), cardiomyopathy, moyamoya, and prothrombotic states including antiphospholipid syndrome, factor V Leiden, antithrombin III deficiency, and protein $\mathrm{C} / \mathrm{S}$ deficiency. ${ }^{3}$ Although these may be contributors to stroke throughout a human lifespan, the higher prevalence of traditional cardiovascular derangements such as hypertension, hypercholesterolemia, diabetes, obesity, and atrial fibrillation among older adults have made the aforementioned conditions more specific to young adults.

An uncommon etiology of cardioembolic stroke in the younger population is atrial myxoma, as seen in the present case. Myxomas are benign cardiac tumors arising from subendocardial mesenchymal cells and are most commonly found in the left atrium. Incidence of cardiac tumors has been reported to be between $0.001 \%$ and $0.3 \%$ in autopsy studies and $0.15 \%$ in major echocardiographic series with approximately $50 \%$ of identified tumors being myxomas. ${ }^{5}$ Myxomas often have a genetic origin and may be found in conditions such as tuberous sclerosis or the Carney complex. ${ }^{6}$ The natural history of these tumors is highly variable. While the majority of patients have cardiac complaints and approximately $10 \%$ of patients never experience symptoms, $29 \%-40 \%$ of cases present with an embolic episode. ${ }^{7}$

The embolic potential of a myxoma is expected to be influenced by tumor size, consistency, friability, and left atrial diameter. While the contribution of each of these attributes to embolization risk is incompletely understood, myxomas with irregular, villous, and friable surfaces are more frequently associated with production of emboli. ${ }^{7}$ The cerebral vasculature is the most common location for embolization from a myxoma and the prevalence of associated strokes has been reported to be $21 \%-29 \% .^{7-9}$

Strokes secondary to atrial myxomas differ from strokes due to other etiologies in some key ways. These patients may be previously asymptomatic or without any known stroke risk factors and a few may have cardiac symptoms due to tumor causing mitral valve obstruction. ${ }^{7}$ Blurred vision has been identified as the most common neurologic symptom in this population and may present alone or in combination with more elaborate deficits such as hemiparesis/plegia. The blood vessels usually occluded are retinal vessels followed by medium-sized cerebral vessels such as $\mathrm{M} 1{ }^{10}$ Of the 
approximately $22 \%$ of patients who may have embolization of a cardiac myxoma, multivessel infarction has been reported in up to $72.7 \%$ of patients. ${ }^{8}$

The response rate of patients to tPA from myxoma-induced AIS is lower than in stroke from other causes. This is primarily due to lysed tumor forming an integral part of the embolus. Therefore, mechanical thrombectomy may be a better option for treatment of these occluded segments, especially when large vessels vascularizing critical brain areas are involved. As demonstrated in the aforementioned case, recurrent strokes may occur unless the atrial myxoma is removed with surgical intervention. Hence patients not undergoing myxoma resection require follow-up for further neurologic episodes.

In the patient described above, an early diagnosis of stroke helped in timely administration of tPA. The large artery occlusion prompted a mechanical thrombectomy, which resulted in a dramatic improvement of her symptoms with minimal residual deficits. Further evaluation revealed an atrial myxoma and definitive treatment was done with surgical removal of the myxoma. Thus, having a high suspicion for cardiac myxoma in cases of AIS in young patients can facilitate a quick diagnosis allowing for initiation of focused management.

Atrial myxomas are an important etiology that should be included in the differential diagnoses of young patients with AIS. Early identification of the cause is of utmost importance as these patients may require IV tPA and mechanical thrombectomy to improve outcome and avoid residual disability. Definitive treatment involves surgical myxoma resection.

\section{Author contributions}

P. Tadi, R. Feroze, P. Reddy, P. Sravanthi, N. Fakhri, R. McTaggart, S. Yaghi, and B. Silver were involved in data collection and development of the manuscript. All authors agree upon the manuscript as written.

\section{Study funding}

This research received no specific grant from any funding agency in the public, commercial, or not-for-profit sectors.

\section{Disclosure}

The authors report no disclosures relevant to the manuscript. Go to Neurology.org/N for full disclosures.

\section{References}

1. Palaniswami M, Yan B. Mechanical thrombectomy is now the gold standard for acute ischemic stroke: implications for routine clinical practice. Interv Neurol 2015;4:18-29.

2. Ji R, Schwamm LH, Pervez MA, Singhal AB. Ischemic stroke and transient ischemic attack in young adults: risk factors, diagnostic yield, neuroimaging, and thrombolysis. JAMA Neurol 2012;70:51-57.

3. Poisson SN, Schardt TQ, Dingman A, Bernard TJ. Etiology and treatment of arterial ischemic stroke in children and young adults. Curr Treat Options Neurol 2014;16: 315 .

4. Maaijwee NA, Rutten-Jacobs LC, Schaapsmeerders P, van Dijk EJ, de Leeuw FE. Ischaemic stroke in young adults: risk factors and long-term consequences. Nat Rev Neurol 2014;10:315-325

5. Reynen K. Frequency of primary tumors of the heart. Am J Cardiol 1996;77:107.

6. Briassoulis G, Kuburovic V, Xekouki P, et al. Recurrent left atrial myxomas in carney complex: a genetic cause of multiple strokes that can be prevented. J Stroke Cerebrovasc Dis 2012;21:914.e1-914.e8.

7. Pinede L, Duhaut P, Loire R. Clinical presentation of left atrial cardiac myxoma: a series of 112 consecutive cases. Medicine 2001;80:159-172.

8. Lee SJ, Kim JH, Na CY, Oh SS. Eleven years' experience with Korean cardiac myxoma patients: focus on embolic complications. Cerebrovasc Dis 2012;33:471-479.

9. Cao GF, Bi Q, Cao L, Wang C. The clinical characteristics of stroke in young patients with cardiac myxoma. Zhonghua Nei Ke Za Zhi 2017;56:263-267.

10. Lee VH, Connolly HM, Brown RD Jr. Central nervous system manifestations of cardiac myxoma. Arch Neurol 2007;64:1115-1120. 


\section{Neurology}

Clinical Reasoning: Mechanical thrombectomy for acute ischemic stroke in the setting
of atrial myxoma

Prasanna Tadi, Rafey Feroze, Pranav Reddy, et al.

Neurology 2019;93; $1572-\mathrm{e} 1576$

DOI 10.1212/WNL.0000000000008321

This information is current as of October 14, 2019

\section{Updated Information \&} Services

References

Subspecialty Collections

Permissions \& Licensing

Reprints including high resolution figures, can be found at: http://n.neurology.org/content/93/16/e1572.full

This article cites 10 articles, 0 of which you can access for free at: http://n.neurology.org/content/93/16/e1572.full\#ref-list-1

This article, along with others on similar topics, appears in the following collection(s):

\section{Cardiac}

http://n.neurology.org/cgi/collection/cardiac

Embolism

http://n.neurology.org/cgi/collection/embolism Stroke in young adults

http://n.neurology.org/cgi/collection/stroke_in_young_adults

Information about reproducing this article in parts (figures,tables) or in its entirety can be found online at:

http://www.neurology.org/about/about_the_journal\#permissions

Information about ordering reprints can be found online:

http://n.neurology.org/subscribers/advertise

Neurology ${ }^{\circledR}$ is the official journal of the American Academy of Neurology. Published continuously since 1951, it is now a weekly with 48 issues per year. Copyright @ 2019 American Academy of Neurology. All rights reserved. Print ISSN: 0028-3878. Online ISSN: 1526-632X.

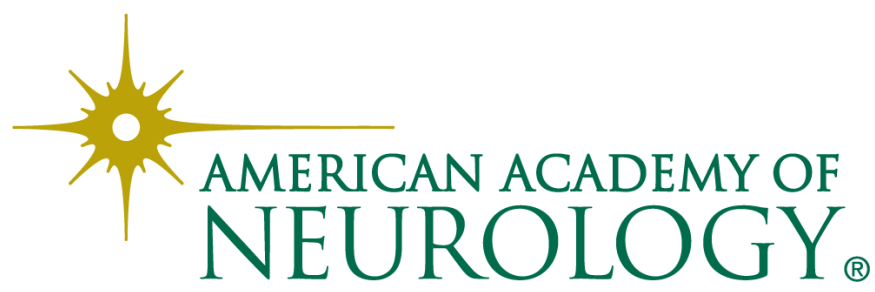

